\title{
The Possible Immunological Pathways for the Variable Immunopathogenesis of COVID-19 Infections among Healthy Adults, Elderly and Children
}

\author{
Ahmed S. Abdulamir ${ }^{1 *}$, Rand R. Hafidh ${ }^{2}$ \\ ${ }^{1}$ Professor in Virology and Infectious diseases, M.B., Ch.B., Ph.D. at Microbiology Department, College of Medicine, Alnahrain University, Baghdad, IRAQ \\ ${ }^{2}$ Associate Professor in Biotechnology and Infectious diseases, Ph.D. at Microbiology Department, College of Medicine, University of Baghdad, Baghdad, IRAQ \\ *Corresponding Author: ahmsah73@yahoo.com
}

Citation: Abdulamir AS, Hafidh RR. The Possible Immunological Pathways for the Variable Immunopathogenesis of COVID-19 Infections among Healthy Adults, Elderly and Children. Electron J Gen Med. 2020;17(4):em202. https://doi.org/10.29333/ejgm/7850

\begin{tabular}{ll}
\hline ARTICLE INFO & ABSTRACT \\
\cline { 2 - 3 } Received: 5 Mar. 2020 & $\begin{array}{l}\text { Novel Coronavirus, COVID-19 discovered in December, 2019 in Wuhan, China started a world-wide epidemic. It is } \\
\text { not clear till now what is the pathogenesis of this virus infection in human or the exact strategies of host immune } \\
\text { response in combating this novel threat to human beings. However, morbidity and mortality of COVID-19 } \\
\text { infections vary widely from asymptomatic, mild to deadly critical. Strangely, children were found to be protected } \\
\text { from severe or deadly critical infections, while elderly and immunocompromised adults are most affected badly } \\
\text { by this virus. It is necessary to disclose the possible viral and host interactions that lead to such variable morbid } \\
\text { effects among patients of COVID-19 infections. }\end{array}$
\end{tabular}

Keywords: Coronavirus, COVID-19, MERS-CoV, SARS-CoV

\section{INTRODUCTION}

Coronaviruses-a family of enveloped positive-strand RNA viruses infects vertebrates. Mutation rates of RNA viruses are greater than DNA viruses, suggesting a more efficient adaptation process for survival. The genome codes for at least four main structural proteins: spike, membrane, envelope, nucleocapsid proteins and other accessory proteins which aid the replicative processes and facilitate entry into cells (1). Coronaviruses have caused two large-scale pandemics in the past two decades, SARS and Middle East respiratory syndrome (MERS). It has generally been thought that SARSr-CoV-which is mainly found in bats-could cause a future disease outbreak (2).

The current classification of coronaviruses recognizes 39 species in 27 subgenera, five genera and two subfamilies that belong to the family Coronaviridae, suborder Cornidovirineae, order Nidovirales and realm Riboviria (3).

COVID-19 is closely related to two bat-derived severe acute respiratory syndrome-like coronaviruses, bat-SL-CoVZC45 and bat-SL-CoVZXC21, but it is more distant from SARS-CoV ( 79\% similarity) and Middle East respiratory syndrome coronavirus (MERS-CoV) ( 50\% similarity). Interestingly, COVID-19 uses the same cell entry receptor-angiotensin converting enzyme II (ACE2)-as SARS-CoV (3-4).

\section{The Course of COVID-19 Epidemic}

On 29 December 2019, Chinese health workers observed a clustering of cases of unusual pneumonia which was clearly associated with a flea market that sells live fish, poultry and animals. One month later, the causative agent was finally recognized as a novel coronavirus. The virus genome was then sequenced and published. This was followed by making up diagnostic kits based on RT-PCR assays. Since then novel corona virus which was later named officially as COVID-19, spread to almost all of the countries in the world. At the time of writing this article, the worldwide confirmed infections passed 100,000 cases with up to $3 \%$ fatality rate (5).

\section{The Transmission and Comparison of COVID-19 to Influenza Viruses}

COVID-19 is a member of coronavirus' family which include hundreds of members infect humans, called common human coronaviruses, namely OC43, 229E, HKU1 and NL63, and other viruses infect animals such as bats, snakes, birds, and others (3). Actually, it is uncommon for animal coronaviruses to transmit from animals to human and cross the species barrier, a phenomenon called spill-over (2). However, if the infective dose was so high and/or animal coronaviruses got mutations favoring transmission to humans, it is possible to see animalto-human transmission of a rarely encountered virus to human population (6).

Reports on COVID-19 indicate that this virus is less virulent than influenza viruses if we took into consideration that human beings have long history with exposure to influenza viruses making majority of humans possess certain degree of immunity against influenza viruses, which is not the case with COVID-19. This explains the keen efforts by health bodies to keep the immune system of human population continuously updated to flu viruses. Nevertheless, this measure is only 
enough to curb seasonal flu but it cannot tackle a possible flu pandemic resulting from a hugely bred/altered influenza virus that humans have no previous records in their log book of immune system.

Well, what knowledge on the fight against influenza virus has to do with COVID-19. From what is shown earlier, we come to understand that if a novel influenza virus emerge like the novel COVID-19, the virulence competition go to the side of influenza without hesitation. This is attributed to the characteristic damaging ability of influenza virus on respiratory mucosa because of neuraminidase surface protein that desquamate respiratory mucosa pretty badly (7). On contrary, common human corona viruses lack this devastating weapon $(3,6)$. And COVID-19 seems no exception. However, COVID-19 unlike common human coronaviruses, tend to infect lower parts of the respiratory system, namely bronchioles and alveoli, and leads, in $15-20 \%$ of cases, to severe pneumonia (56). COVID-19 infects cells by attaching to receptors of Angiotensin converting enzyme -II $(5,8)$. What helps COVID-19 to be dangerous is the lack of memory cells in the immune system to generate adequate and timely immune response to tackle the infection quite early. This leads to the possible deterioration of some patients to critical and deadly stages of the disease by developing severe alveolar pneumonitis, or interstitial pneumonia that might be so severe that most of lung tissue is damaged and oxygen level in blood decreases so severely leading to respiratory failure and consequent heart and renal failure (8).

\section{The Puzzle of the Immunopathogenesis of COVID-19}

There is a puzzling data concerning COVID-19 cases which are hard to be explained. Up to $85 \%$ of infected people experienced mild to moderate infection and around $10 \%$ with severe infections and around 5\% critical cases half of which die (5-7). For a virus totally new to our immune system, these data are encouraging. This notion also indicates that COVID-19 is not that highly virulent virus if compared to a novel influenza virus, if any. In this context, if COVID-19 is not that highly aggressive in damaging the respiratory system, why $5 \%$ of infected people get critically ill who half of them die $(5,9)$. Another piece to this riddle, what is the reason that COVID-19 infections in children and teens are far milder than adult cases, and why the deadly cases mainly seen among elderly and adults with comorbidities like heart disease, diabetes..etc (5,9-10).

It can be obvious from the first glance that the immune system of these sectors of population is the main player in this variable rate of critical and deadly cases. There are several points to be discussed in this endeavor. Most of deadly cases in elderly and weak individuals, with co-morbidities, can be explained that the innate and adaptive arms of their immune system are sub-optimal. This favors COVID-19 to replicate more aggressively and to spread to lower parts of the respiratory system reaching to alveoli and causing pneumonia (9-10). Nevertheless, this can be a straight forward conclusion. But what makes some degree of confusion is the fact that COVID-19 does not attack so aggressively children as elderly. It has been found that children ages 9 and younger are infected as other age groups but they are much less likely to have severe symptoms that are seen in older groups. In fact, many kids never showed symptoms at all.

It is noteworthy to mention that children, especially young children, are more prone to severe respiratory infections caused by almost all other respiratory viruses, than adults (9-
12). Respiratory viruses flourish in bodies where the immune system is either still developing or has started to wear out. Actually, there are several factors make children are more affected by respiratory viruses; these factors include less competent immune system, far less memory cells in the arsenal of children's immune system, shorter bronchial tree making viruses reach alveoli and cause pneumonia more easily than in adults, and preventive measures along with personal hygiene is usually lower in children than in adults (11-12). So what makes COVID-19 infection different from the usual trend of other respiratory viruses? This might be the cornerstone in understanding the very specific course of infection with COVID19 and how the immune response is involved in the development of severe deadly cases.

It was observed that most of the damage to lung tissue in severe cases is due to severe inflammation rather than a direct damaging effect of the virus itself (13). In other words, it is the exaggerated immune response, or the immunopathogenic response, which is responsible for severe pneumonia and consequently respiratory failure. It is noteworthy to mention that the Coronavirus that caused the 2002-2003 SARS outbreak affected adults more than children, with no single person under the age of 24 has died. In severe cases of SARS, a patient would initially have a fever and cough while the virus was rapidly replicating in their lungs. About a week later, they'd spontaneously improve, as their immune system kicked in. But then a second phase of the disease would start, which would be much worse than the first. The second stage wasn't caused by the virus at all, but by patients' runaway immune systems. For reasons that still aren't clear, some people, especially the old and sick, weren't able to turn off their inflammatory response, leading immune cells and inflammation-inducing molecules known as cytokines to flood into the lungs. This socalled a "cytokine storm" (12). It seems that COVID-19 has the same pathogenic effect as SARS 2003. Physicians in China and other countries took this observation into action and started to give potent cortisone-based anti-inflammatory drugs to critically ill patients; however, this kind of therapy is not that successful in stopping progression of the tissue-damaging pneumonia.

\section{The Possible Explanation of the Puzzling COVID-19 Infection}

Taken together from the above mentioned, we come to understand that the critical cases of COVID-19 are mainly in elderly and/or adults with health problems that might compromise their immune system. On the other hand, the main factor leading to critical cases and death has been shown to be an immunopathogenic, or severe inflammatory response that damages lungs and this occur in the same patients who are supposed to be immunocompromised, or at least not immunocompetent. More confusion to this dilemma and against all odds, children were found to be far resistant to severe and deadly critical cases.

In order to shed light on this paradox, we need first to learn some basic things on corona viruses including COVID-19. Corona viruses are enveloped viruses with corona-like projections, or spikes. These spikes are responsible for attacking host cells and get them infected. Once the cell is infected, the viral nucleic acid, a single strand RNA will replicate using viral RNA-dependent-RNA polymerase and replicates in the cytoplasm of the cell. The resulting progeny virions get out from the infected cell by budding where they 
acquire their new envelopes from cell membrane. Hence, COVID-19 infects and hijack host cells but, unlike nonenveloped viruses, does not lyse cells (4-6). Therefore, COVID19 does not apply a direct damaging effect on the infected cells.

So what is the thing which damages patients' lungs? The answer is the immune system itself which mounts a devastating attack on the virally infected cells and kills these cells as a mean to get rid of the parasitic virus inside (12-14). This is exerted by what is called cytokine storm mediated by cell-mediated immune arm of the adaptive immune system, while the humeral immune arm attacks the free viruses outside cells and lock them from entering new cells, this is called neutralization $(5,12,14)$. This is exerted by binding neutralizing antibodies to the crown-like spikes of the virus to prevent the virus from coming in contact with host cells and get them infected. Hence, innate and humeral adaptive immunity prevent infection or hinder the severe infection from occurring, while the cell-mediated immunity focus on terminating the source of infection by eradicating any virally infected cells and get rid of the cellular reservoir of the virus (15).

From the context of the underlying knowledge of COVID-19 and host immune system interaction, the possible explanation of the course of COVID-19 infections is as follows: First, the healthy adults, unlike elderly and weakened individuals, have intact innate immunity along with competent humeral and cell-mediated immunity; the net result is that their immune system can limit the infection from progression and set out recovery within 2-3 weeks from the beginning of symptoms. This is enough to prevent the virus from reaching alveoli in huge numbers like in deadly critical cases. Therefore, these patients recover from mild-moderate infection. Second, elderly patients and/or with co morbidities and compromised immunity do not have the same fit innate and adaptive humeral immune response as healthy adults; therefore, COVID19 keep get lower, in huge numbers, until reaching alveoli beyond which blood circulation is strictly guarded by alveolar lymphocytes and macrophages.

At alveoli, immune system becomes more aggressive as alveoli are the last location before virus invades blood circulation. Alveoli are abundantly guarded by alveolar lymphocytes and macrophages which are the pillars of cellmediated immunity (12). In addition, airway epithelial cells also act as immune effector cells in response to harmful exogenous stimuli as they express on their surface adhesion molecules and secrete various immune molecules such as cytokines, chemokines and other factors that play a major role in cell-mediated immunity (16). Here, the cell-mediated immunity becomes fully in charge and start to eradicate virallyinfected cells at extensive scale response, along with surge in local and systemic cytokines, leading to severe and devastating alveolar and interstitial inflammation leading to damage of lung tissue and filling alveoli with inflammatory exudates. This eventually results in severe hypoxia and respiratory failure and may be collateral damage in downstream organs like liver and kidney (12-15). Accordingly, the shortcomings of innate and humeral immunity in these patients make cell-mediated immunity to mount a vigorous attack at very dangerous area, the alveoli. Here where the catastrophe occurs.

Nevertheless, this scenario does not explain why children do not develop the same immuno-pathogenic course as seen in older patients taken that children, in general, are more prone to develop pneumonia than older individuals. The possible explanation to this observation is that children are less capable to mount a devastating and vigorous cell-mediated attack on alveoli and interstitial tissue of the lung. This might because of the lack of adults-like memory cells specific to other circulating coronaviruses. This might largely be due to lack of sufficient memory cells specific to other coronaviruses. These memory cells are expected to be abundant in adults as they have been exposed to many respiratory infections, whether symptomatic or asymptomatic, caused by common flu-causing coronaviruses. And as known in the field, some of COVID-19 proteins share similarity with these of common human coronaviruses (3-4).

Hence, the theory behind the distinctive behavior of COVID19 among children, healthy adults, and weak co-morbid adults is that there might be a good level of similarity between COVID19 and human coronaviruses antigens presented within MHC-I on the surface of infected cells while no such similarity in $S$ antigen that make up the spikes of the virus. This explanation is backed by the findings of Zhou et al. (5) who found that the most variable and divergent protein in COVID-19 from all other members of coronaviruses is S protein to which neutralizing antibodies are bound. Thus, when the innate and humeral immunity, which faces entirely new $S$ antigen, are not competent enough to curb infection quite early, the cellmediated immunity will be vigorously activated at later stage when COVID-19 infects alveoli. At this stage, cell-mediated immunity could attack another COVID-19 antigen, rather than $\mathrm{S}$ antigen, complexed within MHC-I on the surface of cells; any protein other than S protein of COVID-19 is far less variable than $S$ antigen, as shown by whole genome sequencing of COVID-19 exerted by Zhou et al. (5). A recent study conducted in the Middle East region indicated a noticeable cross-reactivity between MERS-CoV and other human coronaviruses where cross-reactivity was seen by MERS-CoV to at least 3/4 seasonal human coronaviruses (17). In addition, cross-reactivity between SARS and MERS-CoV has also been reported by a 2013 study by Chan et al. who indicated that $25 \%$ of SARS patients had anti-MERS neutralizing antibodies (18).

Accordingly, the less variable COVID-19 antigen within MHC-I most probably share some similarity to antigens of other coronaviruses that have been frequently encountered by adults but not at the same level by children. It has been revealed that people by adulthood, become naturally immune to most strains of coronaviruses circulating in the population while children are more prone to infection to common coronaviruses because they are yet lack immunity to most of the circulating coronaviruses (19). Therefore, children might lack sufficient memory cells to the antigenic repertoire of coronaviruses, including probably some COVID-19crossreactive antigens, leading to much milder cell-mediated immune response and milder inflammation than in adults.

Actually, the suggested immunopathogenesis needs to be investigated thoroughly. This cell-mediated-based immunopathogenic effect can be modulated to the reverse direction. Any intervention with immunomodulatory effect towards T-helper2 might provide life-saving chance to critically ill patients and minimize the damaging effect of inflammatory pneumonia. One of the possible therapies is interleukin-10 which polarizes immune system towards Th2 and away from Th- 1 by inhibiting IFN-gamma and IL-12 and TNF-alpha. A therapeutic clinical trial might shed light on the effect of such immunomodulatory intervention on the morbidity and mortality of critically affected cased with COVID-19. 


\section{REFERENCES}

1. Schoeman D, Fielding BC. Coronavirus envelope protein: current knowledge. Virol J, 2019;16(1):69. https://doi.org/10.1186/s12985-019-1182-0 PMid:31133031 PMCid:PMC6537279

2. Hui DS, E IA, Madani TA, Ntoumi F, Kock R, Dar O, Ippolito G, McHugh TD, Memish ZA, Drosten C, Zumla A, Petersen E. The continuing 2019-nCoV epidemic threat of novel coronaviruses to global health - The latest 2019 novel coronavirus outbreak in Wuhan, China. Int J Infect Dis, 2020;91:264-6. https://doi.org/10.1016/j.ijid.2020.01.009 PMid:31953166

3. Coronaviridae Study Group of the International Committee on Taxonomy of, V. The species Severe acute respiratory syndrome-related coronavirus: classifying 2019-nCoV and naming it SARS-CoV-2. Nat Microbiol, 2020. https://doi.org/10.1038/s41564-020-0695-z PMid:32123347

4. Lu R, Zhao X, Li J, Niu P, Yang B, Wu H, et al. Genomic characterisation and epidemiology of 2019 novel coronavirus: implications for virus origins and receptor binding. Lancet, 2020;395(10224):565-574. https://doi.org/10.1016/S0140-6736(20)30251-8

5. Zhou P, Yang XL, Wang XG, Hu B, Zhang L, Zhang W, et al. A pneumonia outbreak associated with a new coronavirus of probable bat origin. Nature, 2020. https://doi.org/10.1038/ s41586-020-2012-7 PMid:32015507

6. Liu K, Fang YY, Deng Y, Liu W, Wang MF, Ma JP, et al. Clinical characteristics of novel coronavirus cases in tertiary hospitals in Hubei Province. Chin Med J (Engl), 2020. https://doi.org/10.1097/CM9.0000000000000744 PMCid:PMC7028197

7. Krammer F, Smith GJD, Fouchier RAM, Peiris M, Kedzierska K, Doherty PC, et al. Influenza. Nat Rev Dis Primers, 2018;4(1):3. https://doi.org/10.1038/s41572-018-0002-y PMid:29955068

8. Huang C, Wang Y, Li X, Ren L, Zhao J, Hu Y, et al. Clinical features of patients infected with 2019 novel coronavirus in Wuhan, China. Lancet, 2020;395(10223):497-506. https://doi.org/10.1016/S0140-6736(20)30183-5

9. Li Q, Guan X, Wu P, Wang X, Zhou L, Tong Y, et al. Early Transmission Dynamics in Wuhan, China, of Novel Coronavirus-Infected Pneumonia. N Engl J Med, 2020. https://doi.org/10.1056/NEJMoa2001316 PMid:31995857

10. Liu Y, Gayle AA, Wilder-Smith A, Rocklov J. The reproductive number of COVID-19 is higher compared to SARS coronavirus. J Travel Med, 2020. https://doi.org/10.1093/ jtm/taaa021 PMid:32052846
11. Jamison DT. In: Jamison DT, Breman JG, Measham AR, Alleyne G, Claeson M, Evans DB, et al. (Eds.). Investing in Health. In Disease Control Priorities in Developing Countries. Washington DC, 2006. https://doi.org/10.1596/ 978-0-8213-6179-5/Chpt-1

12. Molteni M. Kids Can Get Covid-19. They Just Don't Get That Sick. Available at: https://www.wired.com/story/kids-canget-covid-19-they-just-dont-get-that-sick/ (Accessed 10 March 2020).

13. Tian S, Hu W, Niu L, Liu H, Xu H, Xiao S-Y. Pulmonary pathology of early phase 2019 novel coronavirus (COVID19) pneumonia in two patients with lung cancer. Journal of Thoracic Oncology, 2020. https://doi.org/10.1016/ j.jtho.2020.02.010

14. Mckeever, A. From blood storms to honeycomb lungs, here's an organ-by-organ look at how COVID-19 harms humans. Available at: https://www.nationalgeographic. com/science/2020/02/here-is-what-coronavirus-does-tothe-body/ (Accessed 10 March 2020).

15. McCloskey B, Heymann DL. SARS to novel coronavirus - old lessons and new lessons. Epidemiol Infect, 2020;148:e22. https://doi.org/10.1017/S0950268820000254 PMid:32019614 PMCid:PMC7026896

16. Beck-Schimmer B, Schimmer RC, Pasch T. The airway compartment: chambers of secrets. News Physiol Sci, 2004;19:129-32. https://doi.org/10.1152/nips.01508.2003 PMid:15143208

17. Al Kahlout RA, Nasrallah GK, Farag EA, Wang L, Lattwein E, Muller MA, et al. Comparative Serological Study for the Prevalence of Anti-MERS Coronavirus Antibodies in Highand Low-Risk Groups in Qatar. J Immunol Res, 2019;2019:1386740. https://doi.org/10.1155/2019/1386740 PMid:30906787 PMCid:PMC6398027

18. Chan KH, Chan JF, Tse H, Chen H, Lau CC, Cai JP, et al. Cross-reactive antibodies in convalescent SARS patients' sera against the emerging novel human coronavirus EMC (2012) by both immunofluorescent and neutralizing antibody tests. J Infect, 2013;67(2):130-40. https://doi.org/ 10.1016/j.jinf.2013.03.015 PMid:23583636

19. Begley S. Experts envision two scenarios if the new coronavirus isn't contained. Available at: https://www.stat news.com/2020/02/04/two-scenarios-if-new-coronavirusisnt-contained/ (Accessed 15 March 2020). 